\title{
From the Editor: A Little Something for (Almost) Everyone
}

\author{
Dorothy S. Becvar
}

Published online: 2 February 2011

(C) Springer Science+Business Media, LLC 2011

Over the course of its 70+ year history, family therapy has grown from being comprised of a small group of innovative thinkers and practitioners known mostly to themselves into a large and diverse field that has worldwide recognition as an effective means for helping individuals, couples, and families. What is more, this field is made up of an ever expanding group of professionals who play many different roles and have a wide range of interests. Such variety, of course, is essential and speaks to the health and long-term viability of the field. That is, without the expansion and development of theory our approaches would likely become outmoded and less effective. Without educators and supervisors trainees in the field would have nowhere to turn for the instruction necessary to become well-qualified professionals. Without close scrutiny of our approaches and assessment tools we might find ourselves doing more harm than good.

Thus it is important that journals such as Contemporary Family Therapy continue to support and encourage the various roles and interests of the field's members. Sometimes this happens with special editions comprised of articles devoted to a single topic. Other times journal editors create several sections, with each article fitting into a particular category. And then there are instances, as with the current edition, when there is such a range of topics that there seems to be a little something for (almost) everyone. Accordingly, the menu for this edition follows, with interest group indicated for each. My hope is that readers will find one or more articles that relate(s) to a current area of interest as well as articles that expand their focus to include other areas for exploration. Given the international nature of this journal, I also have indicated the authors' country of origin at the end of each article summary.

For those interested in education-informed practice and practice-informed education: "The Importance of Spirituality in Couple and Family Therapy: A Comparative Study of Therapists' and Educators' Beliefs" by Thomas Stone Carlson, Christi McGeorge, and Amy Anderson sheds light on differences and similarities between those teaching and those practicing relative to the incorporation of spirituality in therapy with clients (USA).

D. S. Becvar $(\bowtie)$

Saint Louis University, 3550 Lindell Boulevard, St. Louis, MO 63101, USA

e-mail: becvards@slu.edu 
For supervisees and their supervisors: "Help Me Help You: Suggested Guidelines for Case Presentation" by Paul Maione offers a framework that is intended to help facilitate the best use of a supervisory session (USA).

For those interested in theory development as it relates to couples: "Differentiation of Self and Separation Anxiety: Is There a Similarity Between Spouses?" by Ora Peleg and Meital Yitzhak provides new thoughts about an important dimension of Murray Bowen's family systems theory (Israel).

For those interested in learning about assessment tools for use with couples in therapy: "Assessing Attachment of Couples in Therapy: A Factor Analysis of the Experiences in Close Relationships Scale" by M. L. Parker, Lee Johnson, and Scott Kettering expands the potential for its use, with implications relative to differences between men and women (USA).

For those interested in practice research: "Marital and Family Therapist's Action Research in Light of Some Research Problems: A One-Cycle Example" by Robert Cvetek, Mateja Cvetek, Tanja Repič, and Saša Poljak attempts to fill an often noted gap by providing a practitioner-friendly approach to research (Slovenia).

For those interested in resources for clients beyond the therapy room: "Stepfamily Education: A Case Study" by Linda Skogrand, Patricia Davis, and Brian Higginbotham speaks to the growth and utility of a model for supporting couples and children who are living in reconstituted families (USA).

For therapists curious about the application of theory to their own families: "Virginia Satir's Family Camp Experiment: An Intentional Growth Community Still in Process" by Russell Haber provides an insider's view of an approach created by one of the original family therapists more than 30 years ago, an approach that continues to evolve today (USA).

Certainly there are many more roles and interests shared by family therapists in various stages of their careers, and who are studying and working in different parts of the world. These, of course, are addressed in other editions and other journals. But the offerings of this edition speak volumes about what professionals currently are involved with and where they would like to see the field grow. I consider this to be very important information and welcome more "news of difference" that may inform all aspects of the marriage and family therapy profession. 